\title{
Valores, la medicina y la docencia
}

\author{
Values, medicine and teaching \\ Federico Leopoldo Rodríguez Weber*
}

Citar como: Rodríguez WFL. Valores, la medicina y la docencia. Acta Med. 2021; 19 (1): 7-8. https://dx.doi.org/10.35366/98562

En el siglo XXI tenemos que reconocer la importancia de hablar a nivel universal de los valores y principios éticos que nos permitan, en nuestro tiempo y época, la convivencia social, así como el desarrollo personal y profesional. No podemos desconocer que la casa es el lugar donde recibimos la formación más importante, es la familia la que influirá en nuestros valores y normas de convivencia.

Todos los seres humanos por naturaleza vivimos en una sociedad y para que ésta sea funcional tenemos que aprender a convivir recibiendo este aprendizaje, como mencionamos anteriormente, de la familia, la escuela, los compañeros y amigos, y de la sociedad por medio de la comunicación, las leyes y demás actividades que caracterizan al entorno donde nos desempeñamos. Cada individuo es producto de su historia, por lo que conocer el origen, evolución, desarrollo, causas y efectos de lo que ha pasado con su vida personal y social, y saber lo que ha sucedido a su alrededor en relación con la construcción de la sociedad, sus orígenes, principios éticos, creencias, creaciones intelectuales, todos ellos en un determinado contexto hacen que cada individuo elija y priorice los valores ante las diferentes situaciones.

Los que estamos involucrados en los procesos de enseñanza no podemos olvidar el compromiso con la formación de estudiantes y en nuestro caso, los involucrados en la formación de médicos, la cual debe incluir los conocimientos, pero también nuestro trabajo debe ser la

\footnotetext{
* Médico Internista, profesor adjunto del Curso de Medicina Interna del Hospital Ángeles Pedregal, Escuela Mexicana de Medicina de la Universidad La Salle (campus México). Profesor titular de la Cátedra de Propedéutica Clínica y Nosología en la misma universidad, Coordinador de pregrado y postgrado del Grupo Ángeles Servicios de Salud (GASS).
}

Correspondencia:

Dr. Federico Leopoldo Rodríguez Weber

Correo electrónico: fweber@saludangeles.com

www.medigraphic.com/actamedica formación de valores como personas en general y como médicos profesionales en particular. Dicho de otra manera, no basta con proporcionar información, sino que nuestro proceso debe desarrollar médicos inteligentes, sensibles, que ejerzan su libertad intelectual, capaces de desarrollar habilidades y destrezas, así como formas de pensar y de comportamiento de acuerdo con su propia escala de valores ante cada situación específica.

Hablar de valores puede representar un concepto filosófico de poca utilidad en la práctica diaria, por lo que buscamos definir este concepto de forma que pueda ser aplicable como el conjunto de normas de convivencia válidas en tiempo y época. No es raro que los valores generen conflicto en su aplicación, por ejemplo, cuando hablamos del derecho a la vida y a la salud, o cuando la profesión es el modus vivendi y en alguna situación se prioriza la retribución económica, o bien, la disyuntiva de utilizar tiempo suficiente para tener una buena relación médico-paciente, etcétera. Y es innegable que cada persona utilizará y modificará su escala de valores y que ésta será fundamental en el reconocimiento que permita determinar qué acciones o cualidades son positivas o negativas, buenas o malas.

Por último, en el caso de nuestra profesión y en el ejercicio de la misma, más aún cuando también estamos involucrados en los procesos de enseñanza para la formación de médicos, debemos saber reconocer nuestro compromiso con la ciencia médica, así como con los enfermos, los alumnos, las instituciones y con la sociedad en general. Pero cumplir con este compromiso no es fácil, contamos con un entorno que constantemente cambia, y que está lleno de problemas de origen diverso, incluyendo diferencias en los criterios entre los propios profesionales que generan una gran variabilidad en la práctica médica, por lo que es importante tener claros los valores, principios y responsabilidades que caracterizan a la profesión médica y a los profesores de la misma reconociendo el mínimo necesario para lograr un desempeño profesional; es esto lo que identificamos como profesionalismo. 
Este mensaje es válido para todos los profesionales, pero especialmente para los docentes, pues la educación desde siempre ha servido para fomentar el desarrollo de valores, haciendo que el médico en formación adquiera una estructura fuerte que le permita identificar prejuicios y rechazarlos y así aproximarse al conocimiento de la verdad. Educar en valores nos permite trascender y formar parte de la historia generacional, pero sobre todo que seamos y enseñemos a ser profesionales humanos. Como nos ha enseñado durante este año la pandemia por el COVID-19, existen valores en la sociedad que se habían perdido o cuyo lugar había sido sustituido en las escalas de valores de la sociedad y de los profesionales en la vida diaria.

Aportemos con la enseñanza y el ejemplo elementos para que las nuevas generaciones tengan claros sus valores y ejerzan nuestra noble labor de manera profesional. 